\title{
KENDALI SUHU INKUBATOR BAYI MENGGUNAKAN PID
}

\author{
Noor Yulita Dwi Setyaningsih \\ Fakultas Teknik, Program Studi Teknik Elektro \\ Universitas Muria Kudus \\ Email: noor.yulita@umk.ac.id \\ Imam Abdul Rozaq \\ Fakultas Teknik, Program Studi Teknik Elektro \\ Universitas Muria Kudus \\ Email: imam.rozaq@umk.ac.id
}

\begin{abstract}
ABSTRAK
Dalam dunia kesehatan khususnya dalam penanganan bayi baru lahir, inkubator merupakan salah satu instrument yang tepat untuk mengatasi permasalahan-permasalahan dalam penanganan bayi baru lahir, salah satu masalah yang sering kali muncul pada bayi baru lahir adalah, bayi baru lahir belum bisa memproduksi panas tubuh secara alami. Yang membuat kestabilan tubuh bayi baru lahir terganggu. Sehingga salah satu parameter yang penting untuk dikendalikan dalam permasalahan ini adalah kondisi suhu ruang inkubator tersebut. Sistem kendali PID digunakan untuk mengendalikan kondisi suhu ruang inkubator tersebut. Sistem kendali yang digunakan pada permasalahan ini adalah sistem kendali digital. Parameter yang digunakan dalam sistem pengendalian ini adalah $\mathrm{P}$, I dan D. Sistem kendali PID . ada tiga kondisi pengendalian yang dilakukan, kendali PI, kendali PD dan kendali PID, dari ketiga sistem kendali yang diterapkan pada kondisi ini, sistem kendali PID merupakan sistem pengendalian yang lebih optimal pada penelitian ini dibandingkan dengan sistem kendali PI. Dengan sistem kendali PID nilai overshoot yang dihasilkan sebesar $8,08 \%$, dan untuk sistem kendali PI nilai overshoot yang dihasilkan sebesar 39,34\%, serta sistem dalam mencapai kondisi steady state menggunakan kendali PID berada pada detik ke 24 dan kendali PI berada pada detik ke 27.
\end{abstract}

Kata kunci: PID, inkubator bayi, suhu, sistem kendali digital, bayi baru lahir, close loop.

\begin{abstract}
In the world of health, especially in the handling of newborns, incubators is one instrument that is appropriate to address the problems in the handling of newborns, one of the problems that often arise in newborns is, the newborn have not been able to produce body heat naturally. Which makes the stability of the newborn's body disturbed. So one of the most important parameters to be controlled in this problem the incubator room temperature conditions. PID control system is used to control the incubator room temperature conditions. Control system used in this problem a digital control system. The parameters used in this control system is P, I and D. PID control system. there are three conditions that do control, PI control, PD control and PID control, the three control systems applied to this condition, PID control system is a control system that is more optimal in this study compared with PI control system. With PID control system overshoot value of $8.08 \%$, and PI control system overshoot value amounted to $39.34 \%$, as well as the system reaches steady state conditions using PID control is located on the second 24 and PI control are in seconds to 27.
\end{abstract}

Keywords: PID, infant incubator, temperature, digital control systems, newborns, close loop.

\section{PENDAHULUAN}

Pengendalian suhu yang dilakukan pada inkubator bayi harus memiliki parameter yang jelas. Inkubator Bayi adalah suatu kotak yang dirancang untuk mempertahankan suhu internal yang konstan dengan menggunakan suatu termostrat [1] [2][3]. Bayi prematur mempunyai kesulitan mempertahankan suhu tubuh yang tetap dan mudah terjadi variasi [4], karena bayi prematur merupakan bayi yang lahir dalam kondisi yang tidak normal, bisa karena berat badan bayi dibawah rata rata ukuran bayi normal ataupun umur kandungan yang belum genap 9 bulan [4][2][5]. Bayi yang baru lahir di Indonesia mempunyai dimensi fisik rata-rata dengan panjang bayi $55 \mathrm{~cm}$, lebar dada bayi $45 \mathrm{~cm}$, dan berat bayi $3 \mathrm{~kg}[6]$.

Kualitas suatu pengendali ditentukan oleh seberapa baik kinerja pengendali tersebut dalam melakukan proses pengendalian terutama pada bidang kendali yang tergolong sulit [7]. Teknik kendali PID merupakan teknik kendali yang banyak diterapkan di bidang industri pada saat ini [7] [8]. Masing-masing aksi kontrol ini mempunyai keunggulan-keunggulan tertentu, dimana aksi kontrol proporsional mempunyai keunggulan risetime yang cepat, 
aksi kontrol integral mempunyai keunggulan untuk memperkecil error, dan aksi kontrol derivatif mempunyai keunggulan untuk memperkecil d_error atau meredam overshot/undershot [9]. Respon suatu plant dapat diatur edemikian baik melalui pemilihan parameter-parameter kendali yang tepat. Penentuan parameter-parameter kendali melalui perhitungan secara matematis membutuhkan pengetahuan model matematis plant . Pemodelan suatu plant tidak sulit dilakukan selama plant tersebut berorde rendah. Kesulitan akan timbul saat plant yang dimodelkan berorde tinggi. Karena itu, penalaan parameter-parameter PID kurang efektif bila dilakukan melalui perhitungan matematis. Salah satu solusi kesulitan tersebut adalah dengan penalaan PID secara otomatik untuk plant yang akan dikendalikan [10]. Tetapi pengendali konvensional PID ini tidak dapat digunakan untuk variabel yang tidak linear dan tidak dapat digunakan untuk pada pengendali multi variabel. Pada bidang kendali yang mempunyai multi variabel dan non linear malah lebih mudah dikendalikan oleh operator (manusia), tanpa harus mengetahui persamaan atau model matematik dari sistem yang dikendalikan [7]. Elemen-elemen kontroler P, I dan D masing masing secara keseluruhan bertujuan untuk mempercepat reaksi sebuah sistem, menghasilkan offset dan menghasilkan perubahan awal yang besar [7] [11] [12].

\section{METODOLOGI PENELITIAN}

Adapun urutan yang dilakukan dalam metode ini dapat dilihat di Gambar 1.

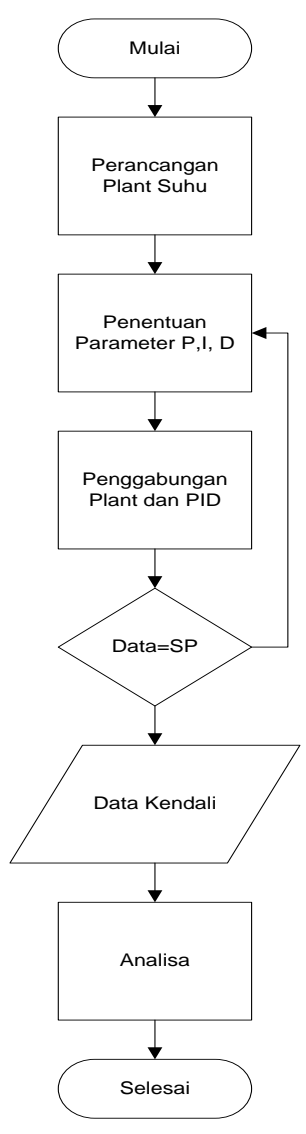

\section{Gambar 1. Langkah Penelitian}

Dari Gambar 1 dapat dilihat proses penelitian yang dilakukan, pertama yang dilakukan adalah dilakukannya perancangan untuk desain dari plant suhu dengan memanfaatkan simulink pada matlab, adapun untuk desain plant suhu yang digunakan pada penelitian ini merujuk dari dari penetian yang sudah ada sebelumnya yaitu penelitian oliveiria,2005 dengan tema penelitian multiple model identification and control of neonate incubators using laguerre basis. Pilot plant dari inkubator itu sendiri terbuat dari sebuah box yang berbahan akrilik transparan yang memiliki tinggi $50 \mathrm{~cm}$, panjang $80 \mathrm{~cm}$ dan lebar $40 \mathrm{~cm}$. dimana model suhu yang digunakan dibangun dari dua macam model yaitu model linier dan non linier [13]. Adapun bentuk model suhu yang telah dibangun dalam Simulink matlab dapat dilihat pada Gambar 2. 


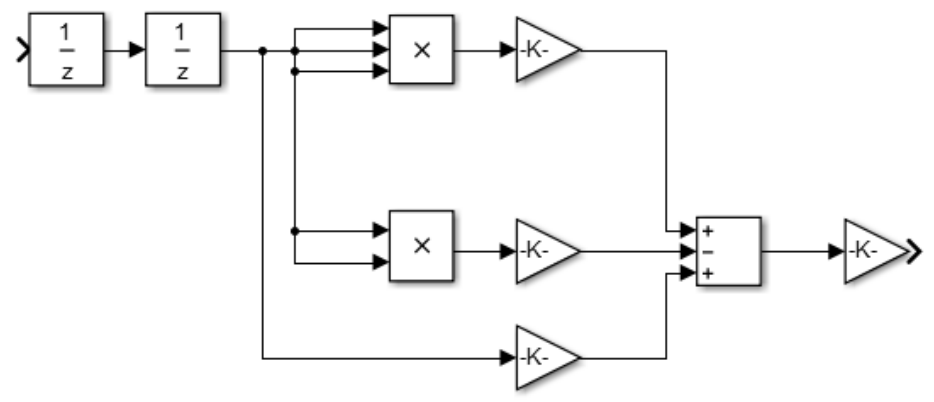

Gambar 2. Model Suhu Pada Simulink

Gambar 2 merupakan desain dari model suhu yang digunakan dalam aplikasi simulink. Plant suhu yang digunakan merupakan model diskrit. Adapun persamaan yang digunakan untuk membangun pembuatan model tersebut adalah persamaan berikut,

$v(k)=0,6946 u^{3}(k-2)-3,3068 u^{2}(k-2)+4,8351 u(k-2)$

Dengan $\mathrm{v}(\mathrm{k})$ merupakan sinyal yang menghubungkan output dari model bagian non-linier dan masukan dari bagian model linier [11]. Selanjutnya setelah mendapatkan model suhu yang ingin dilakukan pengendalian, model ini yang akan digunakan untuk mendapatkan parameter P, I dan D. Penentuan parameter ini memanfaatkan software matlab. Setelah parameter didapat, selanjutnya menggabungkan pengendali PID pada plant, adapun bentuk dari pengendalian ini dapat dilihat pada Gambar 3.

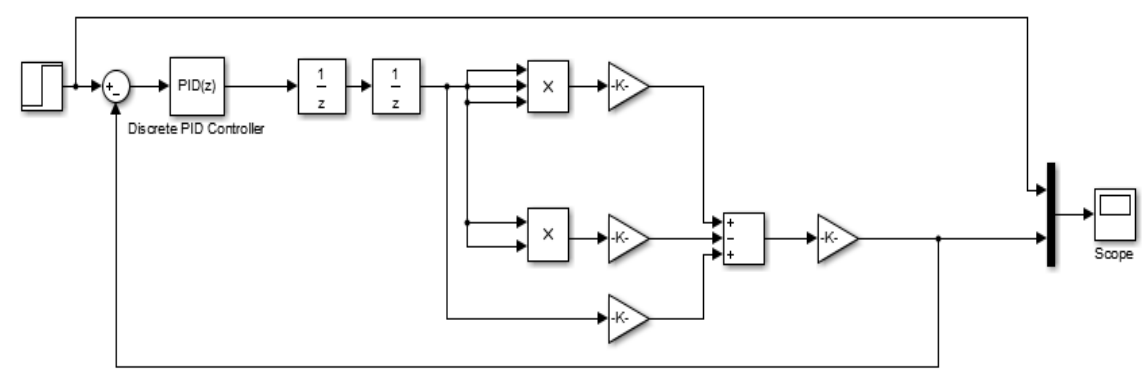

Gambar 3. Kendali PID Pada Plant Suhu

Gambar 3 menunjukkan kombinasi kendali PID pada plant suhu inkubator, dapat dijelaskan bahwa setting point masuk kemudian kendali PID melakukan proses penentuan parameter, selanjutnya akan digunakan untuk melakukan pengendalian plant.

Jika nilai yang dihasilkan atau PV ( Present value ) belum memenuhi dari data SP ( Setting Point ) maka proses akan kembali pada penentuan parameter PID yang digunakan, setelah itu data akan didapatkan dan akan dilakukannya analisa.

\section{HASIL DAN PEMBAHASAN}

Hasil pengendalian suhu pada inkubator bayi menggunakan sistem kendali PID. Ada beberapa pengendalian yang digunakan, yang pertama adalah menggunakan pengendalian PI, untuk desain kendali dapat dilihat pada Gambar 4 dan hasil pengendalian PI pada Gambar 5. Untuk desain pengendalian PD dapat dilihat pada Gambar 6 dan hasil pengendalian PD pada Gambar 7. Sedangkan desain pengendalian PID dilihat pada Gambar 8 dan hasil pengendalian PID pada Gambar 9.

Pengendalian pertama yang dilakukan adalah menggunakan pengendalian $\mathrm{PI}$, dengan paramater $\mathrm{P}=$ 0,0104448992421577 dan parameter $\mathrm{I}=0,0208897984843154$. Berikut desain dari pengendalian PI dan hasil Pengendalian PI. 


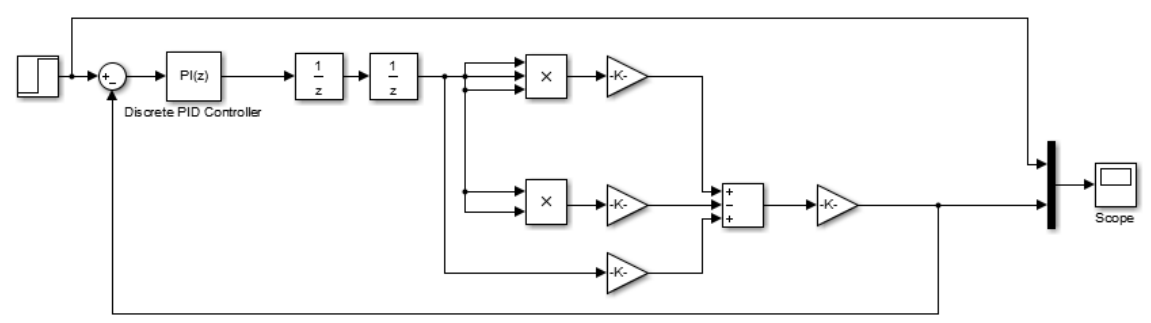

Gambar 4. Pengendalian PI

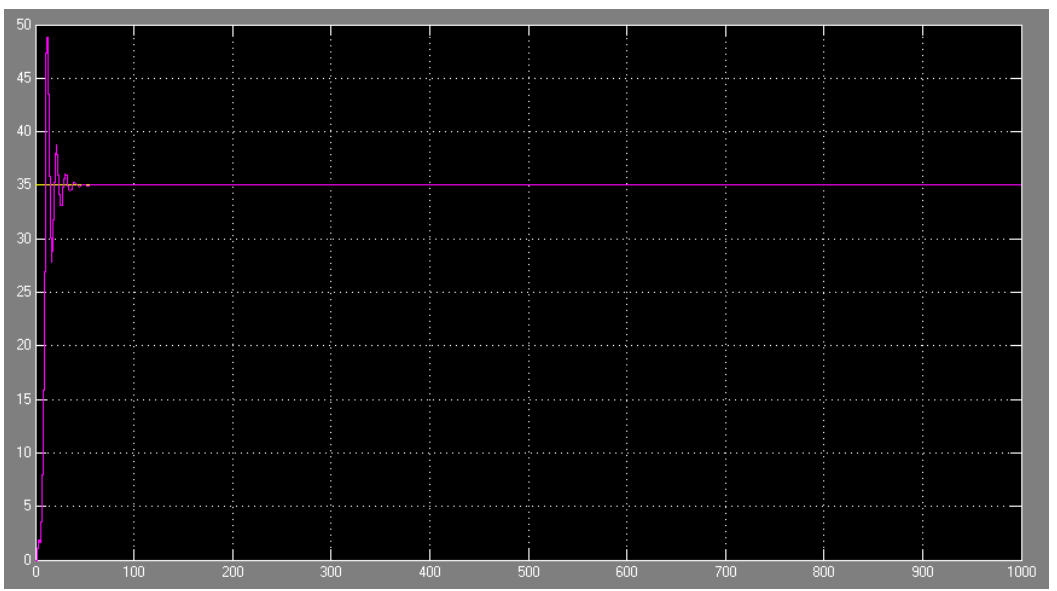

Gambar 5. Hasil Pengendalian PI

Gambar 4 merupakan desain dari sistem kendali PI yang merujuk pada persamaan (1). Kemudian Gambar 5 merupakan hasil pengendalian PI yang dilakukan, dimana sumbu X merupakan waktu yang proses pengendalian dan sumbu Y merupakan data suhu pembacaan pada pengendalian. Nilai setting point yang digunakan dalam penelitian ini adalah kondisi $35^{\circ} \mathrm{C}$. Adapun hasil pengendalian dengan sistem kendali PI dapat dilihat pada Tabel 1.

\section{Tabel 1. Hasil Pengendalian PI}

\begin{tabular}{lc}
\hline Presentase Overshoot & $\mathbf{3 9 , 3 4 \%}$ \\
\hline Waktu Tunda & 9 detik \\
Waktu Naik & 10 detik \\
Waktu Puncak & 12,5 detik \\
Waktu Settling Time & 27 detik \\
\hline
\end{tabular}

Dari Tabel 1 dapat dilihat bahwa waktu yang dibutuhkan sistem untuk mengkondisikan keluaran sesuai dengan masukan yang diharapkan menggunakan sistem kendali PI membutuhkan waktu 27 detik, tapi kelemahan dari sistem kendali PI ini nilai overshoot nya masih tinggi yaitu sebesar 39,34\%. Selanjutnya dengan menggunakan pengendali PD, sistem masih berada pada nilai Setting Point yang sama yaitu $35^{\circ} \mathrm{C}$. Berikut adalah desain pengendali PD dan hasilnya.

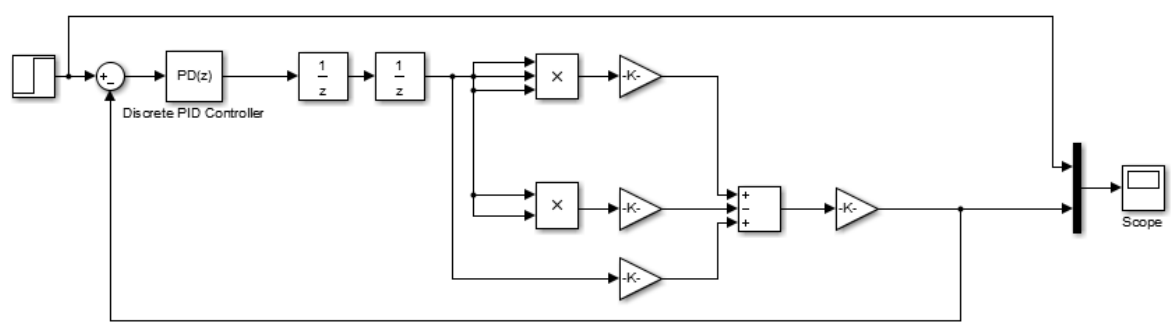

Gambar 6. Desain Pengendali PD 


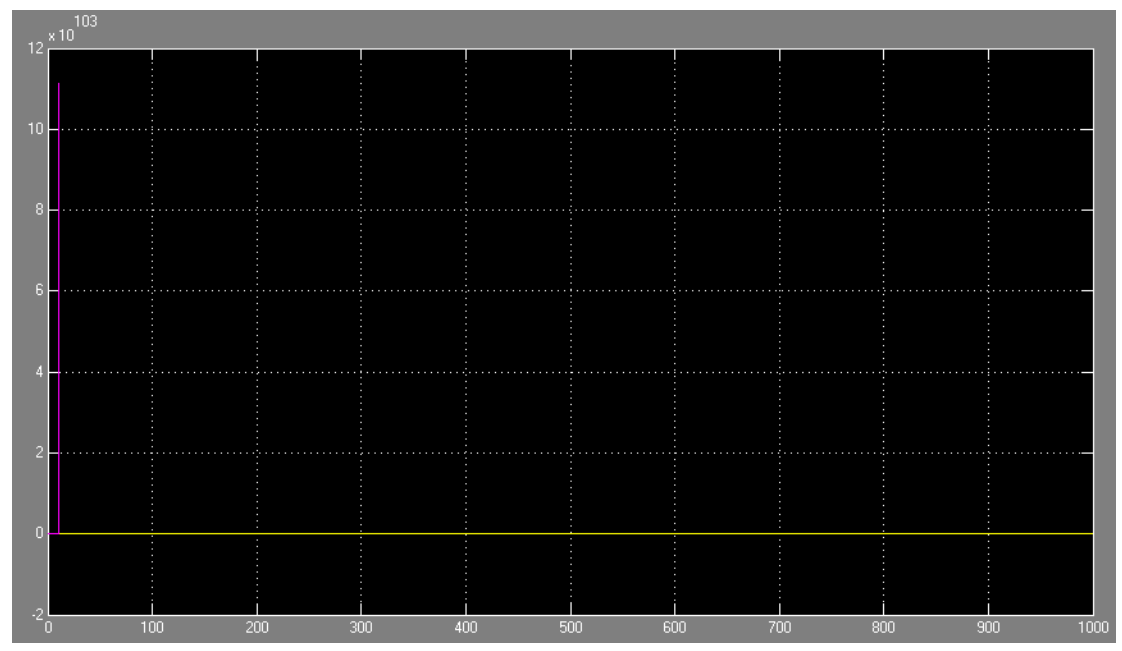

Gambar 7. Hasil Pengendalian PD

Dari hasil pengendalian PD pada Gambar 7 dapat dilihat bahwa, dengan model suhu yang digunakan ternyata sistem kendali PD tidak bisa diaplikasikan pada model ini, terlihat bahwa sistem tidak dapat mengendalikan sesuai dengan kondisi yang diinginkan. Terakhir adalah sistem pengendalian PID, berikut desain dan hasil dari pengendalian PID.

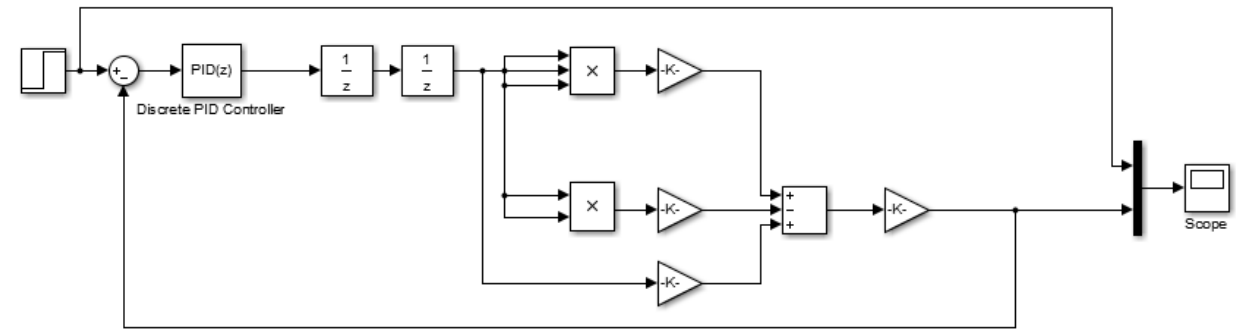

Gambar 8. Desain Sistem Kendali PID

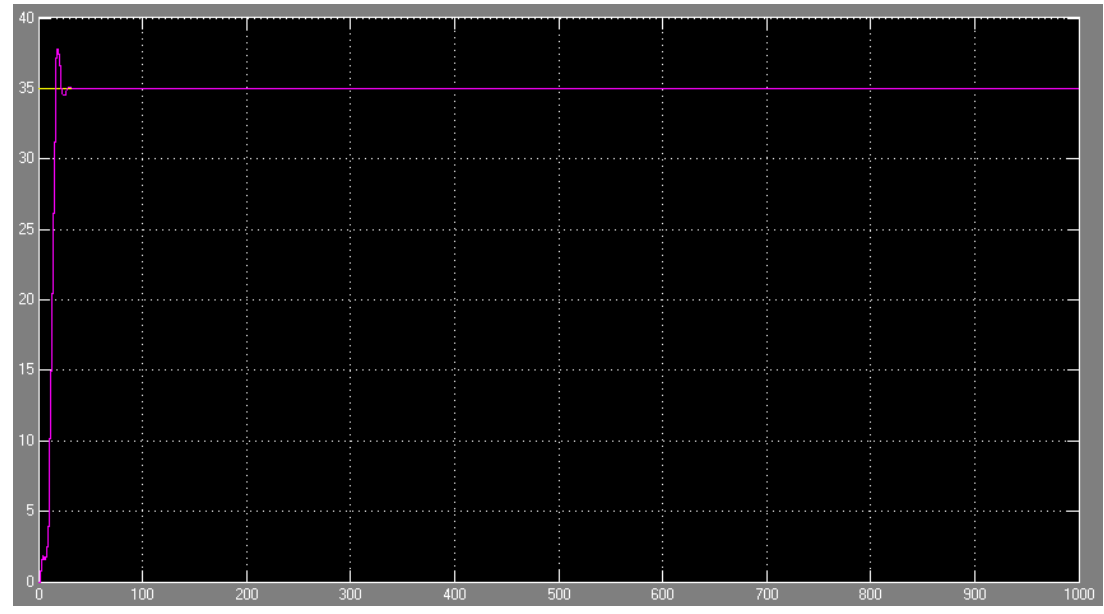

Gambar 9. Hasil Pengendalian PID

Pada pengendalian PID parameter yang digunakan adalah sebagai berikut : Parameter $\mathrm{P}=$ $0.00648020037858366, \mathrm{I}=0.0129604007571673$, dan $\mathrm{D}=0$. Adapun hasil dari pengendalian PID dapat dilihat pada Tabel 2.

Tabel 2. Data Hasil Pengendalian PID

\begin{tabular}{lc}
\hline Presentase Overshoot & $\mathbf{8 , 0 8 \%}$ \\
\hline Waktu Tunda & 13 detik \\
Waktu Naik & 16 detik \\
Waktu Puncak & 18,5 detik \\
Waktu Settling Time & 24 detik \\
\hline
\end{tabular}


Dari Tabel 2 dapat dilihat bahwa sistem ini saat menggunakan kendali PID memiliki waktu pencapaian kondisi steady state lebih cepat dibandingkan dengan kendali PI, yaitu 24 detik, 3 detik lebih cepat dibandingkan dengan kendali PI, serta presentasi overshoot lebih kecil yaitu 8,08\%.

\section{KESIMPULAN}

Dari penelitian ini dapat disimpulkan bahwa:

1) Pada plant suhu yang digunakan dalam penelitian ini hanya bisa dilakukan pengendalian menggunakan sistem kendali PI dan sistem kendali PID.

2) Sistem kendali PID merupakan sistem pengendalian yang lebih optimal pada penelitian ini dibandingkan dengan sistem kendali PI.

3) Dengan sistem kendali PID nilai overshoot sebesar 8,08 \%, sedangakan sistem kendali PI nilai overshoot sebesar 39,34\%, serta sistem dalam mencapai kondisi steady state menggunakan kendali PID berada pada detik ke 24 dan kendali PI berada pada detik ke 27.

\section{DAFTAR PUSTAKA}

[1] E. S. Adhi Ksatria Theopaga, Achmad Rizal, "Design and Implementation Of PID Control Based Baby Incubator," J. Theor. Appl. Inf. Technol., vol. 70, no. 1, pp. 19-24, 2014.

[2] fitri adi iskandarianto catur darmayanto, "Optimalisasi Kelembaban Udara Pada Tabung Baby Incubator Melalui Integrasi Pengendalian Temperatur Dan Kelembaban,” Surabaya, 2007.

[3] Syahrul, "Pengembangan Inkubator Bayi dan Sistem Pemantauan Remote," Tekno Insentif, vol. 6, no. 38, pp. 9-17, 2012.

[4] M. R. APRIYADI, "Miniatur Pemantau Suhu Inkubator Bayi Berbasis Mikrokontroler Atmega 8535 Dan Jaringan Nirkabel," Jakarta, 2012.

[5] K. Suprihatin, "Studi Pengaruh Kontak Kulit Ke Kulit Antara Ayah dan BBLR Terhadap Suhu Tubuh Ayah dan Bayinya di Rumah Sakit Umum Daerah Sidoarjo,” 2012.

[6] Budiono, "Desain dan Pembuatan Inkubator Berdasarkan Distribusi Temperatur," J. GAMMA, vol. 2086-3071, no. September, pp. 140-147, 2012.

[7] D. W. N. Protus Pieter Kalatiku, "Sistem Pengendalian PID yang Diaplikasikan pada Pengendalian Steam Turbin dengan Sigle Variabel Input dan Sigle Output," Smartek, vol. 9, no. 2, pp. 140-154, 2011.

[8] E. D. Saeful Bahri, Husnibes Muchtar, "Prototipe Sistem Kendali PID dan Monitoring Temperatur Berbasis Labview," in Seminar Nasional Sains dan Teknologi 2014, 2014, no. November, pp. 1-5.

[9] S. Bachri, "Sistem kendali Hybrid PID-Logika Fuzzy Pada Pengaturan Kecepatan Motor DC," Makara Teknol., vol. 8, no. 1, pp. 25-34, 2004.

[10] W. Eka Candra Wijaya, Iwan Setiawan, "Auto Tuning PID Berbasis Metode Osilasi Ziegler-Nichols Menggunakan Mikrokontroler AT89S52 pada Pengendalian Suhu," Semarang.

[11] R. E. Ak and E. Iskandar, "Implementasi Sistem Navigasi Behavior Based dan Kontroler PID pada Manuver Robot Maze."

[12] D. I. Pt, E. Nusa, and G. Gresik, "Perancangan Sistem Pengendalian Temperatur pada Reboiler Metanol Recovery Menggunakan Fuzzy Gain Scheduling-PID di PT Eterindo Nusa Graha Gresik," Surabaya.

[13] G. H. C. Oliveira, M. F. Amorim, K. J. Latawiec, C. Pr, and B. Zip, "Multiple Model Identification And Control Of Neonate Incubators Using Laguerre Basis,” 2005. 